\title{
PASADOS IMAGINADOS. A PROPÓSITO DE VIVENCIAS DEL PARTIDO VANGUARDIA POPULAR, DE GERARDO CONTRERAS
}

\author{
Iván Molina Jiménez*
}

\section{Contreras, Gerardo. Vivencias del Partido Vanguardia Popular. San José, Perro Azul, 2008.}

El libro Vivencias del Partido Vanguardia Popular, de Gerardo Contreras, recopila un conjunto de textos relacionados con la historia del Partido Comunista de Costa Rica (PCCR) durante el siglo Xx, a saber: algunas entrevistas realizadas a inicios de la década de 1980 a José Figueres y Arnoldo Ferreto, varios ensayos sobre aspectos específicos de la historia de esa organización, algunas semblanzas de figuras destacadas (Carmen Lyra, Carlos Luis Fallas, Luisa González, Jorge Debravo y Joaquín Gutiérrez) y una extensa conversación con Humberto Vargas Carbonell y Manuel Boza a propósito de los 75 años de la fundación del PCCR.

Los textos indicados tienen un valor fundamentalmente documental, ya que ofrecen, ante todo, versiones de los comunistas (o de sus adversarios, en el caso de Figueres) sobre el pasado de su partido y de su experiencia como militantes. Esto es aplicable, incluso, a los ensayos, en los que prevalece la intención de rescatar la memoria colectiva de esa

Escuela de Historia y Centro de Investigación en Identidad y Cultura Latinoamericanas (CIICLA), ambos de la Universidad de Costa Rica.

IVAN.MOLINA@ucr.ac.cr organización. De esta manera, el presente libro viene a sumarse a una corriente de recuperación de dicha memoria que se inicia tras la guerra civil de 1948, se profundiza tras las múltiples entrevistas dadas por Manuel Mora en las décadas de 1960 y 1970, y culmina con los testimonios publicados por otros dirigentes (como Arnoldo Ferreto, Jaime Cerdas y Eduardo Mora) a partir del decenio de $1980^{1}$.

Un análisis de estos materiales sugiere que, en la primera etapa de ese proceso de rescate, ubicada entre finales de la década de 1940 y mediados de la de 1960, la recuperación de la memoria se orientó a esclarecer las condiciones que condujeron a la ilegalización del Partido Vanguardia Popular y a precisar el impacto que la alianza con el Partido Republicano Nacional había tenido para los comunistas. A partir de la segunda mitad del decenio de 1960 y hasta la crisis de la izquierda, a inicios del decenio de 1980 , el proceso se concentró, con base en las narrativas elaboradas por Manuel Mora, en destacar el papel

1

Para un análisis al respecto, véase: Molina Jiménez, Iván. Los pasados de la memoria. El origen de la reforma social en Costa Rica (1938-1943). Heredia, Editorial Universidad Nacional, 2008. Capítulos 3-5. 
protagónico que tuvieron los comunistas en el origen $y$ defensa de la reforma social del período 1941-1943. Finalmente, tras la crisis indicada, lo que había sido una memoria colectiva esencialmente dominada por los testimonios de Mora se fragmentó, en la medida en que diversos dirigentes, al resaltar su participación en la historia del PCCR, se apartaron de los relatos de Mora o los impugnaron. Algo de esto ya había ocurrido antes, pero en pequeña escala $y$ de manera menos visible públicamente.

El libro de Contreras se ubica dentro de esta última tendencia, como lo demuestra el hecho de que uno de sus aspectos más interesantes es la completa ausencia de la narrativa elaborada por Manuel Mora acerca del origen de la alianza entre los comunistas $y$ el gobierno de Calderón Guardia ${ }^{2}$. En una entrevista que Mora le concedió al historiador Óscar Aguilar Bulgarelli, a mediados de la década de 1960, señaló que un día, alrededor de 1942, en que él pronunciaba un discurso por radio, varios capitalistas lo llegaron a buscar para proponerle que se sumara a un golpe de Estado contra el gobierno. Según Mora, el rechazó la invitación y después de consultar con la dirigencia del PCCR, se dirigió a Casa Presidencial, donde se reunión con Calderón Guardia, a quién le ofreció el respaldo de su partido a cambio de que el gobierno iniciara una política social ${ }^{3}$.

No es casual que esta narrativa fundamental, presente en buena parte de las investigaciones realizadas sobre la década de 1940, desapareciera en el libro de Contreras. Como lo demostró Gustavo Adolfo Soto, en un libro publicado en 1985, la narrativa de Mora adolecía de graves contradicciones cronológicas $y$ de verosimilitud, aspectos que nuevas investigaciones han confirmado ${ }^{4}$. Hoy en día

Contreras. Vivencias. Pp. 13-16 y 179-183.

Aguilar Bulgarelli, Óscar. Costa Rica y sus hechos políticos de 1948 (problemática de una década). San José, Editorial Costa Rica, 1969: 318-320.

Soto, Gustavo Adolfo. La Iglesia costarricense y la cuestión social: antecedentes, análisis y proyecciones de la reforma social costarricense de 1940 1943. San José, Editorial Universidad Estatal a Distancia, 1985: 290-294. se sabe que, contrario a la versión de Mora, la respuesta inicial de los comunistas a la legislación social que promovió el gobierno de Calderón Guardia fue el rechazo, pero que tal actitud cambió rápidamente, a partir de septiembre de 1940, cuando se hizo público que el presidente se proponía impulsar un código laboral. A partir de ese momento, la crítica de los comunistas al gobierno bajó de tono y los comunistas, que antes calificaran a Calderón Guardia de demagógico, ahora empezaron a afirmar que el presidente podía ser una buena persona ${ }^{5}$.

Sin duda alguna, una organización como el PCCR, que tantas veces se vio obligada a cambiar su posición para ajustarse a las circunstancias políticas y electorales del momento, creó las condiciones que, a futuro, llevaron a sus dirigentes a elaborar "ficciones operativas" para salvar las brechas entre la experiencia histórica y la memoria de esa experiencia que era necesario recuperar. Tal dinámica fue potenciada por dos factores: primero, tras la ilegalización posterior a la guerra civil de 1948, uno de los mayores activos que disponía el PCCR era su pasado de lucha a favor de los trabajadores y de la democracia. Con el fin de resaltar tal contribución, era fundamental prescindir, en la memoria colectiva recuperada, de todo aquello que pudiera prestarse para cuestionar al PCCR. Por eso, en la narrativa de Mora la reforma social nace a partir de un golpe de Estado imaginario, que permite dejar en la sombra la respuesta inicial del PCCR a esa reforma.

El segundo factor se refiere a que los comunistas, al fundar su organización en 1931, crearon algo más que un partido político, crearon también una cultura, cuya base fue una crítica sistemática del orden existente, combinada con un conjunto de valores que enfatizaban la lucha contra toda forma de corrupción, la sensibilidad hacia los problemas de los sectores populares y la búsqueda de la justicia social. Por tal razón, dicha cultura atrajo rápidamente la simpatía de algunos de los artistas e intelectuales más destacados del

Molina Jiménez. Los pasados de la memoria. Capítulos 12-13 y 15. 
país, quienes la proyectaron decisivamente en el arte y la literatura. Ciertamente, el partido era la base de esa cultura; pero, en tanto organización política adscrita a un movimiento internacional e integrada en una dinámica electoral, debía responder a demandas - como la solidaridad externa o el cálculo electoral- que tendían a crear una contradicción permanente entre cultura y partido. Esto fue evidente, entre otros casos, cuando la dirigencia llamó a apoyar a Octavio Beeche en la elección de 1936 o se vio obligada a defender el pacto nazi-soviético en 1939.

Por las razones expuestas, en tanto fuentes históricas, las memorias de los comunistas costarricenses - sobre todo las de los dirigentes - deben ser consideradas, con particular criticidad, por los historiadores $y$ otros investigadores sociales. El caso siguiente también es útil para comprender este punto: en una de las entrevistas efectuadas por Contreras, Ferreto afirma que, con vistas a la elección presidencial de 1940, Ricardo Jiménez, en 1939, lideró una alianza con el apoyo de diversos sectores, incluidos los comunistas, y que “... don Ricardo aceptó un programa de izquierda como plataforma de lucha en esas elecciones". Actualmente se conoce que cuando los comunistas se integraron a la alianza, ya Jiménez había renunciado a la candidatura ${ }^{6}$.

Confrontar sistemáticamente las memorias comunistas con los hechos históricos es un procedimiento adecuado no sólo para determinar cuán cerca o lejos están esas memorias de la experiencia histórica, sino para identificar también esas extraordinarias ficciones operativas que, por sí solas, son un interesantísimo objeto de estudio ${ }^{7}$. Desde esta perspectiva, el libro de Contreras ofrece un valioso conjunto de materiales para aproximarse tanto al pasado que los comunistas vivieron, como a los pasados que imaginaron.
6 Molina Jiménez, Iván. Ricardo Jiménez. Capítulo 5. San José, Editorial Universidad Estatal a Distancia, 2008.

\footnotetext{
Acerca de la importancia de investigar esas ficciones, véase: Portelli, Alessandro. "Uchronic Dreams: Working Class Memory and Possible Worlds". Samuel, Raphael y Thompson, Paul (eds.). The Myths We Live By. London, Routledge, 1990: 143-160.
} 